\title{
Phase transformations of $\sigma$-FeCr induced by ball milling
}

\author{
B. F. O. Costa • J. M. Loureiro • G. Le Caër
}

Published online: 9 November 2006

(C) Springer Science + Business Media B.V. 2006

\begin{abstract}
A tetragonal sigma phase $\sigma-\mathrm{Fe}_{0.54} \mathrm{Cr}_{0.46}$ transforms gradually into a bcc phase by ball-milling in argon. Mössbauer spectroscopy shows further the presence of an amorphous phase. It starts to form after $25 \mathrm{~h}$ of milling in our experimental conditions.
\end{abstract}

Key words $\mathrm{Fe}-\mathrm{Cr} \cdot$ sigma phase $\cdot$ ball-milling $\cdot$ amorphization $\cdot$ Mössbauer spectroscopy

\section{Introduction}

Nearly equiatomic binary $\mathrm{Fe}-\mathrm{Cr}$ alloys and the multinary alloys derived from them are technologically important materials because of their high-temperature corrosion and mechanical resistance. At high temperature, these body centered cubic (bcc) alloys are however not stable. The precipitation of a sigma $\mathrm{Fe}-\mathrm{Cr}$ phase $[1,2]$ makes for instance the steel very brittle.

Phase transformations in nanocrystalline materials (grain size $d<100 \mathrm{~nm}$ ) can condition some of their applications, as reported for instance for $\mathrm{Fe}-\mathrm{Cr}$ and $\mathrm{Fe}-\mathrm{Cr}-\mathrm{Sn}$ nanostructured alloys [3, 4]. Recently, a study of phase transformations occurring during long-time annealing in $\mathrm{Fe}-\mathrm{Cr}$ films showed that an amorphous phase is formed along with the crystalline phases expected for Cr-rich alloys [5].

The behaviour under milling in vacuum of a sigma $\mathrm{Fe}-\mathrm{Cr}$ phase was studied earlier by Bakker et al. [6-8]. The sigma phase is not stable and transforms into a bcc nanostructured phase which is the sole phase identified from X-ray diffraction patterns. However, this

B. F. O. Costa $(\bowtie) \cdot$ J. M. Loureiro

Departamento de Física, Universidade de Coimbra, P3000-516 Coimbra, Portugal e-mail: benilde@ci.uc.pt

G. Le Caër

GMCM UMR CNRS 6626, Universite de Rennes I, Campus de Beaulieu, Bat. 11A, F35042 Rennes

Cedex, France 
Figure $1 \mathrm{X}$-ray diffraction patterns of $\mathrm{Fe}_{0.54} \mathrm{Cr}_{0.46}$ milled for different times. The first pattern corresponds to the starting tetragonal sigma phase. The bottom pattern is that of the as-cast bcc alloy.

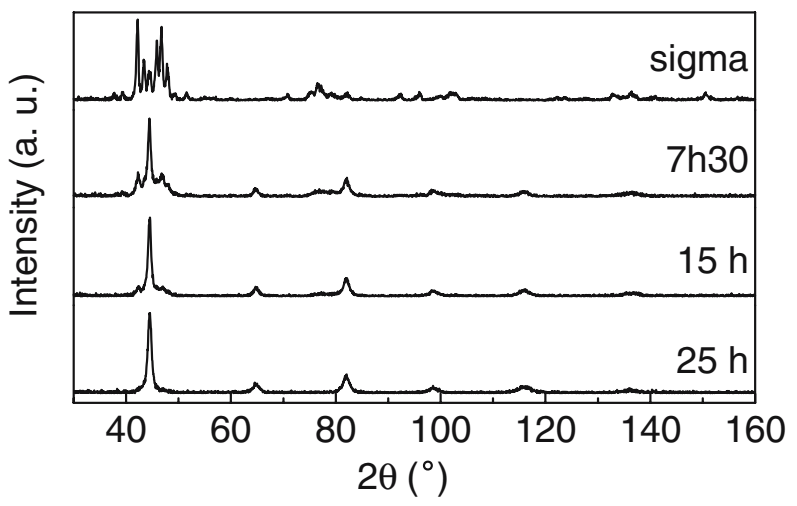

(a)

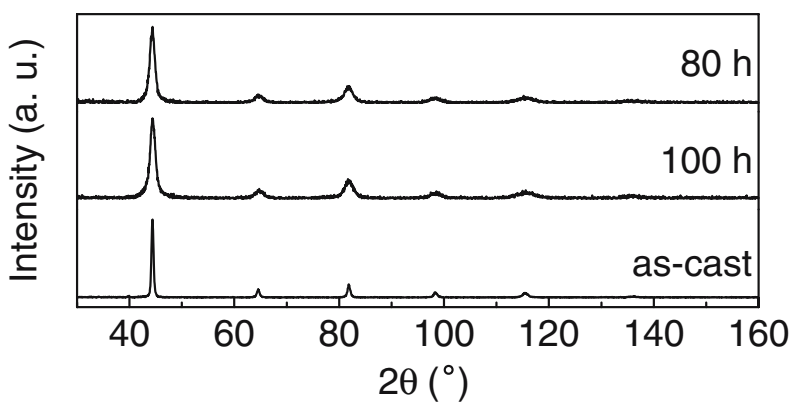

(b)

interpretation does not account for the variation of the low-temperature magnetisation with milling time. The magnetisation expected for a coarse-grained bcc $\mathrm{Fe}-\mathrm{Cr}$ alloy with the same composition $[9,10]$ is about $2 \mu_{B} /$ at. Fe instead of the reported value of $1.2 \mu_{B} /$ at. Fe. This large difference cannot be explained by the effect on magnetic properties of the decrease of the bcc grain size into the nanometer range as proposed. For instance the magnetisation of alpha iron remains practically unchanged in such conditions. Similarly, the mean magnetic hyperfine fields of coarse-grained $\mathrm{Fe}_{0.51} \mathrm{Cr}_{0.49}$ are essentially identical $(<B>=16 \mathrm{~T})$ when the alloy is filed $(d=250 \mathrm{~nm})$ or when it is ball-milled $(d=25 \mathrm{~nm})$ despite coherent domain sizes $d$ which differ by an order of magnitude [11]. Further, a contamination by steel coming from milling tools would contribute to a Fe-enrichment of the milled powders and thus to an increase of the measured magnetic moment. At least two assumptions can be put forward to explain a magnetisation decrease: (a) the formation of an amorphous phase $[12,13]$, which is non-magnetic in the studied concentration range and is possibly favoured by the presence of oxygen in ball-milled alloys [14]; (b) a phase separation with a significant amplitude which is difficult to evidence by X-ray diffraction in such alloys.

As a significant amount of an amorphous phase is however not seen on the X-ray diffraction patterns, we started an investigation of the stability of a sigma-FeCr alloy under high-energy ball-milling in argon, using Mössbauer spectroscopy as the main characterization technique of the structural changes. 
Figure 2 RT ${ }^{57} \mathrm{Fe}$ Mössbauer spectra as a function of milling time. The top spectrum is that of the starting sigma phase.

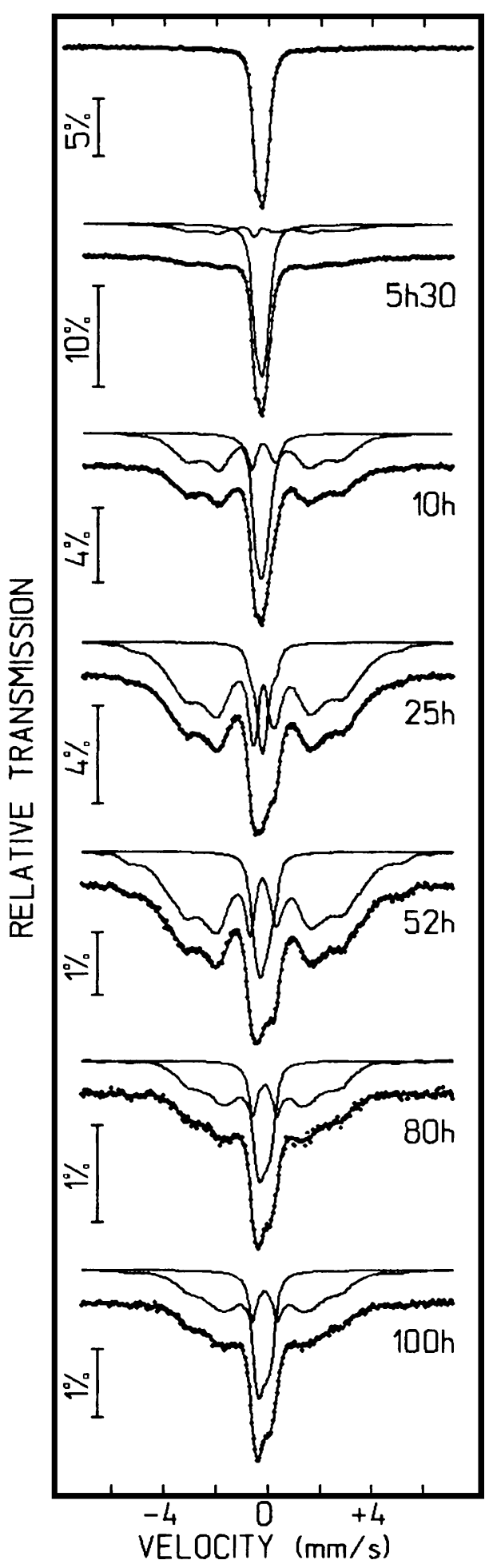


Figure 3 DSC trace of the $\mathrm{Fe}_{0.54} \mathrm{Cr}_{0.46}$ sample milled for $100 \mathrm{~h}$.

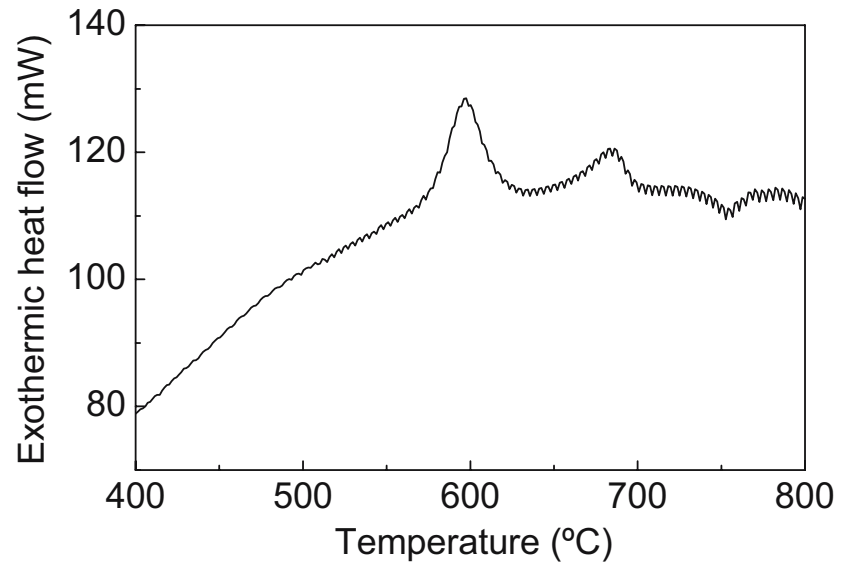

\section{Experimental details}

A bcc $\mathrm{Fe}_{0.536} \mathrm{Cr}_{0.464}$ alloy was prepared by melting together appropriate amounts of $\mathrm{Fe}$ (99.9+\% purity) and $\mathrm{Cr}(99.995 \%$ purity) under argon in an induction furnace. The composition, near the centre of the $\sigma$ phase domain, was chosen to be close to that studied by Bakker et al. [6-8]. The sigma phase was formed by annealing the as-cast bcc alloy in vacuum at $700^{\circ} \mathrm{C}$ for $100 \mathrm{~h}$. It was powdered in an agate mortar into particles with a mean size of about $90 \mu \mathrm{m}$. A mass of $5 \mathrm{~g}$ of $\sigma-\mathrm{FeCr}$ was then ball-milled in a Fritsch P0 vibratory mill with a hardened steel vial and ball. The latter has a diameter of $5 \mathrm{~cm}$ and a mass of $500 \mathrm{~g}$. The vial was sealed under argon atmosphere at the start and after every $100 \mathrm{~min}$ of milling. The mill was working at its maximum amplitude of vibration.

Microprobe analysis was used to determine the composition of the alloy. X-ray diffraction (XRD) was performed at room temperature using $\mathrm{Cu} \mathrm{K} \mathrm{K}_{\alpha}$ radiation $(\lambda=$ $0.154184 \mathrm{~nm}) .{ }^{57} \mathrm{Fe}$ Mössbauer spectra were recorded at room temperature (RT) in a transmission geometry using a standard constant acceleration spectrometer. $\mathrm{A}^{57} \mathrm{Co}$ source in $\mathrm{Rh}$ matrix with a strength of $\approx 35 \mathrm{mCi}$ was used. The experimental spectra were analysed by a constrained Hesse-Rübartsch method [15], which yields a hyperfine magnetic field distribution, $\mathrm{P}(\mathrm{B})$. Lorentzian line-shapes were employed in this procedure. The ${ }^{57} \mathrm{Fe}$ isomer shifts are given with respect to $\alpha$-Fe at RT.

Differential Scanning Calorimetry (DSC) in an argon flow was used to study the transformations of the final as-milled samples during heating from $\mathrm{RT}$ to $800^{\circ} \mathrm{C}$ at a rate of $40^{\circ} \mathrm{C} / \mathrm{min}$. The saturation magnetization of the final sample was determined with a SQUID magnetometer at a temperature of $4.2 \mathrm{~K}$.

\section{Results and discussion}

Figure 1 shows X-ray diffraction patterns (XRD) recorded from powders milled for different times and for comparison, that of the bcc coarse-grained as-cast alloy. The XRD pattern of the starting material is characteristic of the $\sigma$-phase. The intensities of the $\sigma$-phase diffraction peaks decrease steadily with milling time $t_{m}$ and the peaks of the $\alpha$ phase appear progressively. After $25 \mathrm{~h}$ of milling and for longer milling times, only the bcc peaks are seen (Figure 1b). The peaks are broadened due to the decrease of the mean 


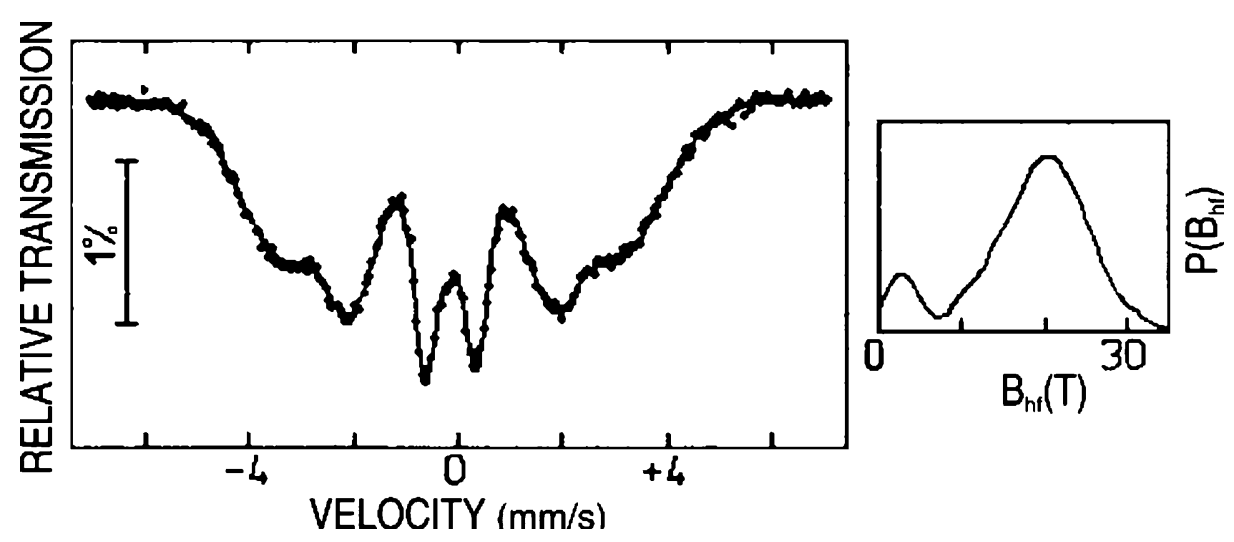

Figure 4 RT ${ }^{57} \mathrm{Fe}$ Mössbauer spectrum and hyperfine field distribution of the sample milled for $100 \mathrm{~h}$ and then annealed at $600^{\circ} \mathrm{C}$ for $6 \mathrm{~min}$.

crystallite size and to strain. As expected, the peaks of the XRD pattern of the as-cast alloy are much narrower than those of ball-milled samples. The mean grain size, determined from the widths of the XRD peaks by the Williamson-Hall method, is $7 \mathrm{~nm}$ for the sample milled during $100 \mathrm{~h}$ and the microstrain is $1.3 \%$.

Figure 2 shows RT ${ }^{57} \mathrm{Fe}$ Mössbauer spectra of the FeCr sample milled for the indicated periods. The first spectrum corresponds to the starting sigma phase which is paramagnetic at RT with an average isomer shift of $-0.17(2) \mathrm{mm} / \mathrm{s}$. A broad magnetic component, associated with the magnetic alpha phase, appears with increasing $t_{\mathrm{m}}$. The contribution of this phase increases until about $25 \mathrm{~h}$ of milling. At this stage, the shape of the central peak clearly changes and its relative contribution increases with $t_{m}$. The paramagnetic contribution can no more be attributed to the sole sigma phase. Another phase transformation is clearly occurring while XRD patterns show only a broadening of the peaks of the bcc phase. The average hyperfine field is 18.5(2) $\mathrm{T}$ and the average isomer shift is $-0.02(2) \mathrm{mm} / \mathrm{s}$ for the sample milled for $100 \mathrm{~h}$. The fraction of 'magnetic' $\mathrm{Fe}$ is about $66 \%$. A DSC trace of the latter sample is shown in Figure 3. The two exothermic peaks, located at about $600^{\circ} \mathrm{C}$ and $680^{\circ} \mathrm{C}$, are attributed to a two-step crystallization of an amorphous phase as advocated in [16].

Thus, we attribute the central peak of the Mössbauer spectra to an amorphous phase with an average isomer shift of $-0.08(2) \mathrm{mm} / \mathrm{s}$ in agreement with the results of Xia et al. [13].

The sample milled for $100 \mathrm{~h}$ was annealed at $600^{\circ} \mathrm{C}$ in vacuum for 6 min and a Mössbauer spectrum and an XRD pattern were subsequently recorded at RT. The Mössbauer spectrum (Figure 4) shows a magnetic phase corresponding to the bcc $\mathrm{Fe}-\mathrm{Cr}$ phase with an average hyperfine magnetic field $\langle H\rangle=18.2(2) \mathrm{T}$ and an average isomer shift $<\mathrm{IS}>=-0.05(2) \mathrm{mm} / \mathrm{s}$ while the XRD peaks are narrower than they are before annealing. The mean crystallite size and the microstrain are found to be $13 \mathrm{~nm}$ and $0.66 \%$, respectively.

The X-ray diffraction results that we obtain are similar to those of Bakker et al. [6-8]. The broad peaks were attributed by them to a bcc solid solution with a small grain size. They also attributed the small saturation magnetization values to the nanocrystalline size of domains.

The saturation magnetization of the sample milled for $100 \mathrm{~h}$ is measured to be of $1.130 \mu_{\mathrm{B}} /$ at. Fe, a value which is similar to that obtained by Bakker et al. [8]. It is $1.871 \mu_{\mathrm{B}} /$ at. Fe for 
the same sample annealed at $600^{\circ} \mathrm{C}$ for 6 min while the value given by Aldred [9] for a bulk coarse-grained bcc alloy of the same composition is close to $2 \mu_{\mathrm{B}} /$ at. Fe. The amorphous phase is thus not fully crystallized as suggested by the small contribution seen in the central part of the spectrum of Figure 4a and reflected by a peak at low field in the corresponding $\mathrm{P}$ (B) distribution (see also [16]).

The sample milled for $100 \mathrm{~h}$ contains 1.2 at. \% $\mathrm{O}$ as determined by its combustion in an oxygen determinator equipped with a solid state infrared detector. Fnidiki et al. [17] showed recently how the presence of significant amounts of oxygen in the grain boundaries of ballmilled FeCr alloys favours the formation of a 'disordered' phase. The oxygen content found here is however smaller than that investigated in the latter work. As discussed in more detail in [16], the formation of an amorphous phase at grain boundaries favoured by the presence of oxygen, or even that of an amorphous-bcc composite with amorphous layers surrounding bcc grains, appears to be a reasonable assumption both consistent with the Xray diffraction pattern of a bcc phase and the change of magnetic properties. In a dynamical equilibrium phase diagram of near-equiatomic $\mathrm{Fe}-\mathrm{Cr}$ alloys milled under vacuum, the domain of amorphization is expected to be shifted downwards to smaller injected powers with respect to that of $\mathrm{Fe}-\mathrm{Cr}$ alloys milled in the presence of residual gases which stabilize the amorphous phase [16]. An amorphous $\mathrm{Fe}-\mathrm{Cr}$ phase can indeed be formed in experimental conditions in which oxygen does not play a significant role [5, 12].

\section{Conclusions}

The sigma phase, whose composition is here $\mathrm{Fe}_{0.54} \mathrm{Cr}_{0.46}$, is not stable during high-energy ball milling either in argon or in vacuum [6-8]. The transformation does not yield a sole bcc $\mathrm{Fe}-\mathrm{Cr}$ phase as concluded from the X-ray diffraction patterns. Mössbauer spectroscopy shows that the formation of the bcc phase occurs together with a partial amorphization of the ball-milled sample. Amorphization, which is known to be favoured by the presence of oxygen, might however be largely of intrinsic origin as discussed further in [16].

\section{References}

1. Kubachewski, O.: Iron-Binary Phase Diagrams, p. 185. Springer, Berlin (1982)

2. Dubiel, S.M., Inden, G., Metalkd, Z.: 78, (1987)

3. Costa, B.F.O., Le Caër, G., Ayres de Campos, N.: Phys. Status Solidi (a) 183, 235 (2001)

4. Costa, B.F.O., Le Caër, G., Luyssaert, B.: J. Alloy Compd. 350, 36 (2003)

5. Levin, A.A., Meyer, D.C., Gorbunov, A., Mensch, A., Pompe, W., Paufler, P.: J. Alloy Compd. 360, 107-117 (2003)

6. Bakker, H., Zhou, G.F., Yang, H.: Prog. Mater. Sci. 39, 159 (1995)

7. Yang, H., Di, L.M., Bakker, H.: Intermetallics 1, 29 (1993)

8. Yang, H., Bakker, H.: Math. Sci. Eng. A181/A182, 1207 (1994)

9. Aldred, A.T.: Phys. Rev., B 14, 219 (1976)

10. Aldred, A.T., Rainford, B.D., Kouvel, J.S., Hicks, T.J.: Phys. Rev., B 14, 228 (1976)

11. Delcroix, P., Le Caër, G., Costa, B.F.O.: J. Alloy Compd. ISMANAM 2005, Paris 4-7 July 2005 (in press)

12. Xia, S.K., Baggio-Saitovitch, E., Larica, C.: Phys. Rev., B 49, 927 (1994)

13. Xia, S.K., Baggio-Saitovitch, E., Rizzo Assunçao, F.C., Pena Rodriguez, V.A.: J. Phys., Condens. Matter 5, 2729 (1993)

14. Lemoine, C., Fnidiki, A., Lemarchand, D., Teillet, M J.: J. Phys. Condens., Matter 11, 8341 (1999)

15. Le Caër, G., Dubois, J.M.: J. Phys. E 12, 1083 (1979)

16. Costa, B.F.O., Le Caër, G., Loureiro, J.M., Amaral, V.S.: J. Alloy Compd. 424, 131-140 (2006)

17. Fnidiki, A., Lemoine, C., Teillet, J.: Physica. B 363, 271 (2005) 